\title{
Video Observations and Model Predictions of Depth-Induced Wave Dissipation
}

\author{
Stefan G. J. Aarninkhof and B. G. Ruessink
}

\begin{abstract}
Time-averaged video observations of the nearshore zone show the process of wave breaking as one or more white alongshore bands of high intensity, corresponding to the preferential location of breaking-wave dissipation on one or more sandbars. Across a known depth profile, similar bands of dissipation can be predicted with existing wave transformation models based on the wave energy balance. This opens up possibilities for estimating bathymetry from video observations by processing observed intensities into a model-predicted proxy of wave dissipation and the inverse modeling of this dissipation proxy into depth. The objectives of this paper are: 1) to present a technique for processing time-averaged cross-shore image intensity profiles into profiles that solely contain the contribution due to wave breaking and 2) to empirically determine which modeled wave dissipation proxy relates best to the cross-shore shape of the obtained breaking-induced intensity. The processing technique involves the removal of background illumination and noise, and, most importantly, a correction for white foam that after being generated in the breaking process remains floating at the water surface. This foam thus contributes to high image intensities but is not predicted by wave transformation models. Based on video and bathymetric data collected at the double-barred beach at Egmond aan Zee, The Netherlands and a standard wave transformation model containing the wave and roller energy balances, we find that the modeled cross-shore distribution of the dissipation of the energy of the surface roller (the white aerated mass of water at the breaking-wave front) matches the observed cross-shore shape of breaking-induced intensity well. Other hypothesized dissipation proxies result in a larger $(>10 \mathrm{~m})$ seaward bias in the locations of maximum breaking-induced intensity and model-predicted dissipation or do not predict the cross-shore change in the area below the breaking-induced intensity bands correctly.
\end{abstract}

Index Terms-Nearshore, optical imaging, sea surface, wave breaking.

\section{INTRODUCTION}

$\mathbf{T}$ HE nearshore zone, extending from the beach to water depths of about $10 \mathrm{~m}$, is probably the most dynamic environment of any oceanic domain. High-energy sea and

Manuscript received April 14, 2004; revised July 21, 2004. This work was supported in part by the Delft University of Technology Interfaculty Research Centre "Observation of the Earth and Earth's Crust" Program, in part by the Dutch Ministry of Transport and Public Works (Rijkswaterstaat), in part by the Delft Cluster Project Coasts (03.01.03), and in part by the European Union CoastView Project under Contract EVK3-CT-2001-0054. The Argus video technique was developed with funds generated by the Coastal Imaging Laboratory, Oregon State University.

S. G. J. Aarninkhof is with the Marine and Coastal Management Division at WLIDelft Hydraulics, Delft, The Netherlands (e-mail: stefan.aarninkhof@ wldelft.nl).

B. G. Ruessink is with the Department of Physical Geography, Faculty of Geosciences, Institute for Marine and Atmospheric Research, Utrecht University, 3508 TC Utrecht, The Netherlands (e-mail: g.ruessink@geog.uu.nl).

Digital Object Identifier 10.1109/TGRS.2004.835349 swell, causing considerable erosion of the beach and adjacent loss of dunes and property, alternate with prolonged periods of low-energy conditions, during which the beach accretes. Nearshore depth information is indispensable for a careful policy to manage the coastal zone. Also, knowledge of nearshore bathymetry is an important naval objective, related to navigation and to amphibious operations near beaches. Scientifically, spatial and temporal depth variability is the end product that many nearshore models, aiming to help in understanding nearshore behavior and forecasting its future, will predict. Conventional in situ measurement techniques for surveying nearshore bathymetry, such as shipborne sonar-based or amphibious soundings, are expensive and limited to quiescent conditions, not resulting in long-term (years) high-resolution (daily-weekly) time series of nearshore bathymetry required for many societal and scientific purposes.

Various remote sensing methods have been explored for surveying nearshore depth. One group of methods, an overview of which can be found in [1], is based on light penetration in the water column and the subsequent reflection off the sea bed. Multispectral [2], [3] and hyperspectral [4] technology, light detection and ranging (LIDAR) technology [5], or combinations of these technologies [6] belong to this group. All these technologies are often troubled by spatial variations in bottom type, which cause different substrate reflectance, and rely on optically clear water, which implies that they are essentially limited to tropical areas. In a second group of methods, characteristics of the sea surface are used to estimate depth. An often applied method within this group is based on the analysis of a sequence of (instantaneous) images or cross-shore pixel arrays acquired with, for instance, shore-based [7] or airborne [8], [9] optical systems, or X-band [10] or S-band [11] radar. Gradients in the phase difference between (processed) intensities at two closely spaced pixels provide an estimate of the local wavenumber, which then is inverted to depth using linear wave theory's dispersion relationship. Whereas depth estimates seaward of the breaker zone are accurate (Stockdon and Holman [7] report typical errors of $\approx 5 \%$ of the observed water depth), wave nonlinearities and the difference in optical signatures of breaking and nonbreaking waves cause depth estimates further onshore to be highly inaccurate. For instance, Stockdon and Holman [7] and Holland [12] show differences between estimated and observed depths of more than $1 \mathrm{~m}$ in depths $<3-4 \mathrm{~m}$. This is unfortunate, as it is within the breaker zone where spatial and temporal depth variations are largest, and accurate estimates are most urgently required.

Our work on estimating depth from remote sensing data belongs to the second group of methods as well. Our proxy signal 

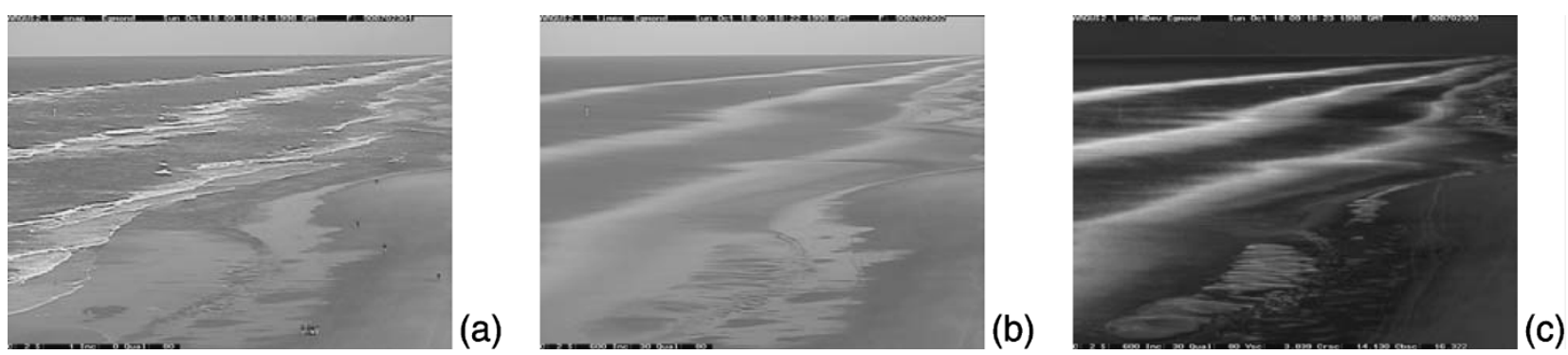

Fig. 1. Example of a (a) snapshot, (b) time exposure, and (c) variance image. The images were collected with camera 2 of the Egmond aan Zee station on October 18, 1998, GMT $09 \mathrm{~h}$. The white stripes in (a) are individual waves breaking on the two subtidal sandbars and at the shoreline; see also Fig. 2. The darker areas in between the breaker zones correspond to bar troughs. The dry beach is visible in the lower right corner of (a) and (b).

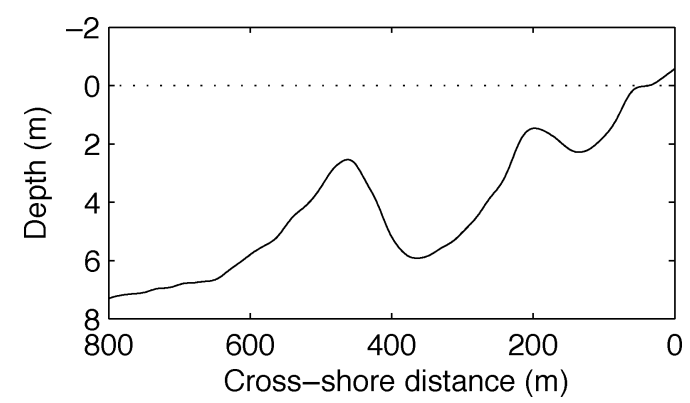

Fig. 2. Depth versus cross-shore distance $(x)$ at Egmond aan Zee, surveyed on October 18, 1998. The horizontal dotted line corresponds to mean sea level. The shallow parts near $x \approx 450$ and $x \approx 200 \mathrm{~m}$ are the outer and inner subtidal sandbar, respectively, and are associated with the left and middle breaker zone in Fig. 1(a) and (b). The third (right) breaker zone in Fig. 1(a) and (b) is the shoreline break on the intertidal bar near $x \approx 50 \mathrm{~m}$.

for depth is related to the depth-induced breaking (dissipation) of the incident waves. The white aerated mass of water, which is formed on the shoreward facing side of a breaking wave and is known as the surface roller, results in a high-intensity signal [13], [14], as can be seen in the snapshot image ("photo") in Fig. 1(a). It is obvious from the example snapshot image that, in the cross-shore direction (roughly from left to right in the image), zones with intense wave breaking alternate with zones without wave breaking. Because nearshore wave breaking is largely depth-induced, the breaker zones are located above shallow parts of the nearshore, known as sandbars, whereas in the deeper parts between the sandbars (sandbar troughs) wave breaking is virtually absent; see also Fig. 2. Even though it is obvious from a snapshot image where waves are predominantly breaking (and, thus, where the sandbars are located), the breaker zones are revealed more clearly by taking the mathematical average of a series of regularly sampled snapshots taken over a 10-min period [Fig. 1(b)]. The averaging removes the statistical nature of the incident wave height, resulting in relatively smooth intensity bands that can be followed in the alongshore direction.

Considerable effort has been devoted to linking cross-shore $(x)$ time-averaged intensity profiles $I(x)$, which can be obtained from images like Fig. 1(b), to cross-shore wave dissipation profiles that can be predicted readily from existing, widely accepted time-averaged wave-transformation models (e.g., [15] and [16]), e.g., see [13], [17], and [18]. The primary purpose of this effort was to establish whether temporal variations in the location of peaks in $I(x)$ collected from a succession of time-averaged images reflected changes in the location in the underlying sandbars or variations in the location of wave breaking over a temporally unchanging depth profile. For this purpose, a simple comparison of the location of the observed intensity and modeled dissipation peaks sufficed. However, when attempting to retrieve depth profiles, the cross-shore shape of $I(x)$ is relevant as well. Aarninkhof et al. [19] scaled observed $I(x)$ into profiles of the modeled dissipation proxy $E_{r} / c^{2}$, where $E_{r}$ is the energy of the surface roller and $c$ is phase speed of the waves, which through the inverse modeling of the roller energy balance (e.g., [20]) can be converted into an estimate of a cross-shore depth profile. Whereas results for the single-barred beach at Duck, NC were quite promising (deviations of 10-20 cm near the bar crest and 30-40 cm in the bar trough), results for the double barred beach at Noordwijk, The Netherlands were far less successful. Here, the relative magnitude of the intensity maxima over the two bars was found to be opposite to the maxima of $E_{r} / c^{2}$, inducing unrealistic cross-shore bar shapes and depth errors of up to $2 \mathrm{~m}$ in the inner bar trough [21]. Also, later work on the transformation of image intensity into an optical dissipation proxy [22] showed [19]'s approach to be rather crude. Most notoriously [13], [22], part of the foam that is generated during wave breaking remains floating at the sea surface. Clearly, this foam contributes to $I(x)$ but it is unrelated to any modeled wave dissipation proxy.

The aim of this paper is to present a technique for processing time-averaged cross-shore image intensity profiles into profiles that solely contain the contribution due to wave breaking and to empirically determine which modeled wave dissipation proxy relates best to the cross-shore shape of the obtained breaking-induced intensity. Results from the depth inversion using this dissipation proxy will be presented in a future contribution. The structure of this paper is as follows. In Section II, we briefly describe the applied Argus [23] video system. Section III shows how the wave-breaking-induced part can be isolated from $I(x)$ and Section IV details the applied wave-transformation model. In Section V, we determine which modeled dissipation proxy relates best to the obtained breaking-induced intensity, using data collected hourly for six weeks in 1998 at the double barred beach of Egmond aan Zee, The Netherlands. The paper is finalized with various concluding remarks.

\section{Shore-BAsed Video Remote SENSING}

An Argus system typically comprises four or five video cameras that span a $180^{\circ}$ view and allow full coverage of an about 3-6 km (in the alongshore) stretch of coast. The cameras are 


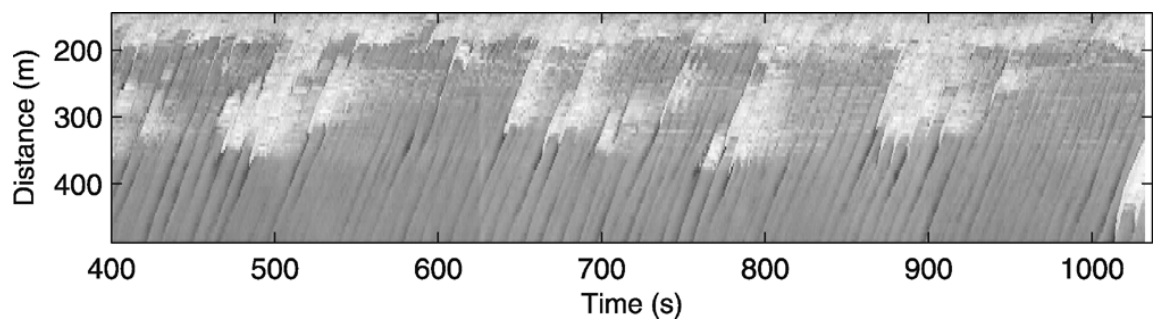

Fig. 3. Example of a cross-shore intensity timestack sampled with $2 \mathrm{~Hz}$ from Duck camera 3 on November 14, 1997, GMT $17 \mathrm{~h}$. The cross-shore direction is positive offshore. The slightly curved patterns are individual waves propagating onshore. The lower intensities $(x \approx 350-450 \mathrm{~m})$ that occasionally precede breaking on the bar at $x \approx 250-350 \mathrm{~m}$ represent the (dark) shoreward facing slopes of steep shoaling waves [7].

mounted on top of a high viewpoint (usually a high building, cliff, or purpose-built tower) and are connected to a computer that controls the hourly image collection and communicates daily to the outside world by phone line. Each standard hourly collection consists of three types of oblique images (Fig. 1), collected for each of the station's cameras. A snapshot image [Fig. 1(a)] serves as simple documentation of conditions but offers little quantitative information. Ten-minute time exposures of the nearshore wave field [Fig. 1(b)] average out natural modulations in wave breaking to reveal a smooth band of white which has been shown to be an excellent proxy for the subtidal sandbar morphology [13], [17]. Variance images [Fig. 1(c)] help identify regions whose intensities change during data collection (e.g., the sea surface) from those whose intensities are time-independent (e.g., the dry beach). In addition to these routinely collected images, dedicated sampling schemes can be designed to collect instantaneous $2-\mathrm{Hz}$ intensity time series at pixels along a cross-shore or an alongshore array. This yields a timestack image, an example of which is shown in Fig. 3. The work presented in this paper is based on time exposure, variance, and timestack images.

Quantification of image features requires accurate georeferencing of oblique video data and a good understanding of the cross-camera variation of pixel resolutions. Image coordinates $(u, v)$ are transformed into real-world location $(x, y, z)$ using the colinearity equations [24]. In the present work, the camera orientation angles (the tilt $\tau$, azimuth $\phi$, and roll $\sigma$ ) and the effective focal length $f$, which directly relates to the camera horizontal field of view $\delta$ [13], were calculated by using a number of ground control points to optimize the colinearity equations. In this optimization the camera position was constrained to surveyed values [24] and the measured offshore water level was used as the rectification level. Prior to the transformation the images were corrected for radial distortions in the lens and pixel nonsquareness resulting from small differences in sampling frequency between the camera and the image acquisition hardware [24].

The theoretical accuracy of video cameras is given by the footprint dimensions of individual pixels. The pixel footprint has a nearly rectangular shape with a larger boresight length $l$ than cross-bore width $w$, given by

$$
w=\frac{R \delta}{N_{u}}
$$

and

$$
l=\frac{R \delta}{\left(N_{u} \cos \tau\right)}
$$

in which $R$ is the distance between the camera and the location $(x, y)$ of interest and $N_{u}$ is the number of horizontal pixels composing the image. Generally, the pixel footprint is oriented obliquely to the shoreline. Thus, $w$ and $l$ deviate from the crossshore and alongshore resolution, which are usually of interest in nearshore applications. Using the angle between the azimuth and the shoreline, $w$ and $l$ are transformed to cross-shore and alongshore dimensions.

An analysis of the errors involved with the procedures for georeferencing and image rectification is provided by [25]. Using the $95 \%$ confidence intervals around the angles $\phi, \delta$, $\tau$, and $\sigma$ as a measure of the error in the individual angles, [25] found that errors are typically less than $0.2^{\circ}$ for $\tau$ and $\phi$ and less than $1^{\circ}$ for $\delta$ and $\sigma$, indicating that the methodology for georeferencing generally yields consistent results. Even though the absolute value of the error in $\tau$ may be relatively small, the accuracy of the rectification procedure is dominated by errors in this angle, yielding positional errors of about five times the dimensions of a pixel footprint for a stand-alone $\tau$ offset of $0.2^{\circ}$ [25]. However, the procedure for georeferencing is self-correcting, in the sense that errors in a single angle are compensated by an offset of the other angles, yielding a total positional error of about the pixel accuracy [25]. As projection errors associated with an inaccurate estimate of the rectification level (typically the measured tidal level) are an order of magnitude smaller than the dimensions of a pixel footprint (at least for the stations considered here), Van Enckevort [25] concluded that image errors are of pixel magnitude.

The comparison between video-based breaking-induced intensities and modeled dissipation proxies is based on data collected at the double-barred at Egmond aan Zee, The Netherlands. We specifically chose a double-barred site, as [19]'s results show that intensity profiles from a single-barred beach are not sufficiently discriminating to determine which modeled dissipation proxy has the same cross-shore structure as breakinginduced intensity. As detailed below, the development of the foam removal technique required an analysis of timestack images. Such images are not routinely collected at Egmond, and we therefore resort to timestack images collected at Duck, NC, a single-barred site facing the Atlantic Ocean. The Egmond and Duck cameras are mounted on top of an $\approx 48.5$ - and 44-m high tower, respectively. 


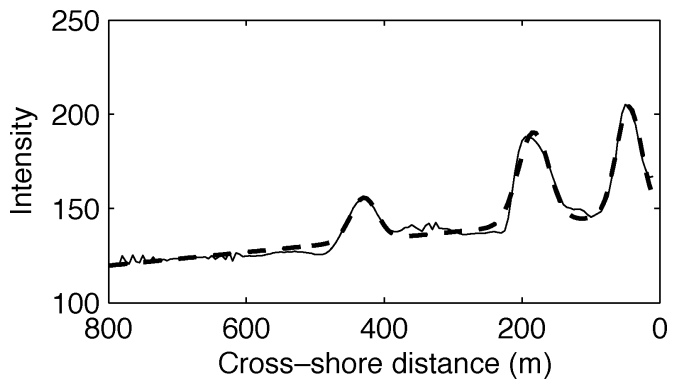

Fig. 4. Example of (solid line) $I(x)$ and (thick dashed line) $I_{G}(x)$ at Egmond aan Zee, The Netherlands. The peaks around $x=430 \mathrm{~m}$ and $x=180 \mathrm{~m}$ represent wave breaking at the outer and inner subtidal bar, respectively; the peak at $x=50 \mathrm{~m}$ corresponds to the shoreline break, compare to Fig. 2 .

\section{IMAGE PROCESSING}

\section{A. Removal of Background Illumination and Noise}

Fig. 4 shows a typical cross-shore time-averaged (i.e., taken from a time-exposure image) intensity profile $I(x)$ at Egmond aan Zee (or, for that matter, any barred beach). It comprises a relatively large background level $I_{0}$, a mildly sloping linear trend $m_{I} x$ (where $m_{I}$ is the constant of proportionality), and a number of Gaussian type, somewhat noisy bumps associated with wave breaking on each bar and at the shoreline. Thus, $I(x)$ can be approximated as [26]

$$
I(x) \approx I_{G}(x)=I_{0}+m_{I} x+\sum_{i=1}^{N_{G}} G_{i}(x)
$$

in which $I_{G}(x)$ is the approximation of $I(x), N_{G}$ is the number of Gaussian-type peaks, and $G(x)$ is given by

$$
G(x)=A_{G} \exp ^{-\left(\frac{\left(x-\mu_{G}\right)}{\sigma_{G}}\right)^{2}}
$$

where $A_{G}, \mu_{G}$, and $\sigma_{G}$ represent a measure for the height, mean location, and width of a dissipation peak, respectively. The number of Gaussian shapes to be fitted matches the number of regions of distinct wave breaking over sandbars or at the shoreline, determined from a threshold procedure stating that a wave breaking induced intensity peak should involve an intensity increase of at least $35 \%$ of the difference between the maximum and minimum value of $I$. Values of $I_{0}, m_{I}$, and of $A_{G}, \mu_{G}$, and $\sigma_{G}$ for each peak were computed using nonlinear least-squares data fitting by the Gauss-Newton method. As can be seen in Fig. $4, I_{G}(x)$ approximates $I(x)$ smoothly, effectively removing noise from the raw intensities. Also, $I_{G}(x)$ does not contain the small intensity reductions immediately seaward of the regions of wave breaking present in $I(x)$. These dips, caused by the dark front face of shoaling waves at the onset of breaking [7] (Fig. 3), do not relate to any physical process incorporated in wave transformation models. The background illumination level is assumed to equal $I_{0}+m_{I} x$ and is subtracted from $I_{G}(x)$. The wave breaking related component $I_{b}(x)$ of $I_{G}(x)$ is thus given by

$$
I_{b}(x)=\sum_{i=1}^{N_{G}} G_{i}(x)
$$

\section{B. Removal of Persistent Foam}

Two sources of white foam contribute to $I_{b}(x)$. The first is the foam associated with the aerated roller at the face of a breaking wave, the second is the foam that escapes from the water column after being trapped in the column during the breaking process and that subsequently remains floating on the sea surface for up to several wave periods. In Fig. 3, both sources are clearly visible: the sudden increase in intensity is related to the roller, the more patchy high intensities ("horizontal stripes") following the passing of the roller reflect persistent foam. To relate pixel intensities to a model-predicted proxy of wave dissipation, the roller induced contribution to $I_{b}(x)$ needs to be isolated by removing the intensity contribution of persistent foam. This can be achieved through application of a scaling factor $f_{s}(x)$ to $I_{b}(x)$, which reflects the relative importance of roller induced pixel intensities as a fraction of the combined intensity impact of the wave roller plus persistent foam, as a function of the cross-shore location

$$
I_{r}(x)=f_{s}(x) I_{b}(x)
$$

To find a suitable $f_{s}$ parameterization, instantaneous $2-\mathrm{Hz}$ time series sampled in individual pixels (Fig. 5) collected at Duck were investigated in detail. Such a time series is obtained by taking a slice from a timestack image (Fig. 3) at some crossshore location. Generally, pixel time series show a roughly constant intensity level at deep water where wave breaking is absent. In the region of initial wave breaking, individual breaking events initiate a sudden increase in the intensity level [Fig. 5(a) and (c)]. Occasionally, this rise is preceded by an intensity dip related to the dark face of a wave near the onset of breaking [7]. As air bubbles, trapped in the water column during wave breaking, escape they may cause persistent wave foam which causes the water surface to be white after the passage of the turbulent roller. The latter processes govern the time scale of the intensity drop after the passage of a breaking wave (i.e., the length of the "tail" of a breaking wave as observed from the intensity time series). Fig. 5(a) and (c) shows typical examples of a slow and rapid intensity drop, respectively.

Further onshore, wave breaking intensifies with decreasing water depth. Consequently, the time window between wave breaking events ("intensity bursts") narrows and the fraction of breaking waves $Q_{b}$ increases. If the decay time scale is relatively large with respect to the wave period $T_{p}$, breaking waves catch up with the persistent foam of the preceding breaking wave, yielding a relatively constant high-intensity signal when all waves are breaking (saturated breaking, $Q_{b} \approx 1$ ); see Fig. 5(b). If the decay time scale is relatively small with respect to the wave period $T_{p}$, pixel intensities drop before the arrival of the next breaking wave, yielding a strongly peaked intensity signal [Fig. 5(d)].

A 10-min time-averaged video observation of nearshore wave breaking is based on many snap shot observations of breaking and nonbreaking waves. To quantify $f_{s}$ and hence $I_{r}$, we need to model the intensity signal of an individual breaking wave, assess which part of the signal is roller related and average the roller induced contribution over time while accounting for the crossshore varying fraction of breaking waves. Based on Fig. 5, the 

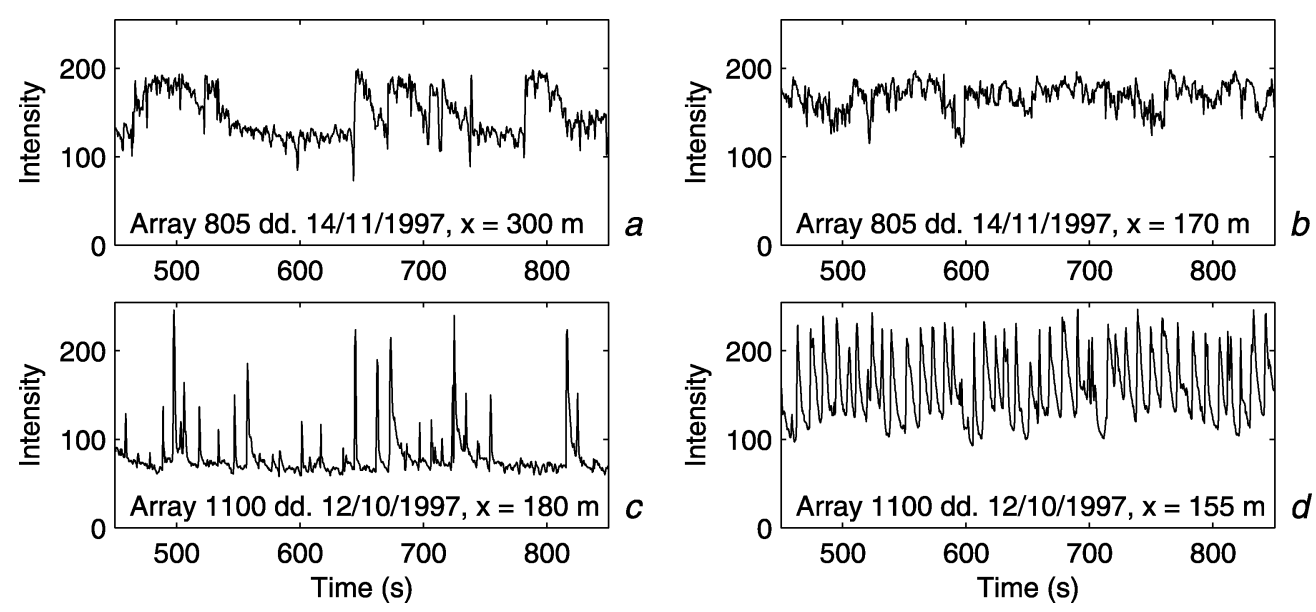

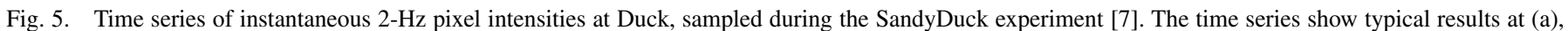

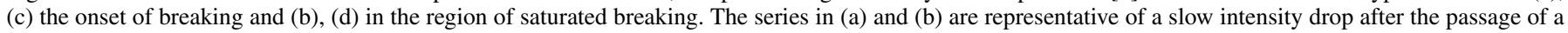
roller, while (c) and (d) show typical results of a rapid drop.
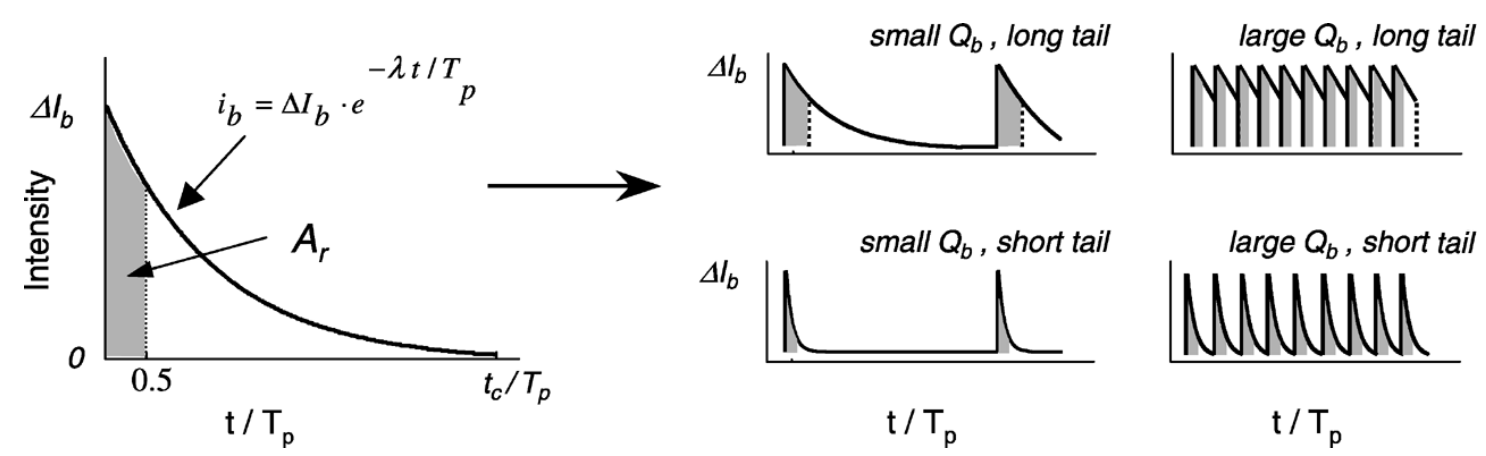

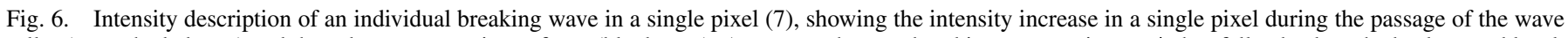

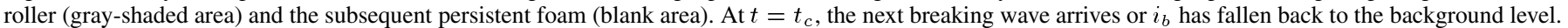
The four plots on the right represent the four situations shown in Fig. 5.

instantaneous intensity signal of an individual breaking wave $i_{b}$ above the background level can be described by (Fig. 6)

$$
i_{b}(t)=\Delta I_{b} \exp ^{-\lambda t / T_{p}}
$$

where $\Delta I_{b}$ is the initial intensity increase at the time of the arrival of the roller, $t$ is time ( $t=0$ corresponds to the arrival of the surface roller), and $\lambda$ is a nondimensional decay factor accounting for the time scale of the intensity decay after passage of the roller relative to the wave period $T_{p}$. The roller induced contribution to $i_{b}(t)$ is separated from the persistent foam induced part by assuming that $i_{b}(t)$ is roller related for $0 \leq t \leq 0.5 T_{p}$, and induced by persistent foam for $t>0.5 T_{p}$. In Fig. 6 , the integrated roller induced contribution $A_{r}$ to $i_{b}(t)$ is shaded for the four typical video conditions discussed here, that is long/short tail breaking (small and large $\lambda$, respectively) in combination with initial/saturated breaking (small and large $Q_{b}$, respectively; see Fig. 5). Admittedly, it appears odd that we scale the intensity decay of an individual breaking wave with a period that is based on a series of waves. A physically more correct scaling period would have a time scale that represents the time window between the entrapment of bubbles in the water column and its subsequent release to the water surface. This is, as discussed at length in [27], a poorly understood topic, and, therefore, we have taken the pragmatic assumption of implementing $T_{p}$ in (7).
Now suppose that $i_{b}$ of a single breaking wave at location $x$ has fallen back to the background level at $t=t_{c}$ or, which is possible as well, is cut off at $t=t_{c}$ owing to the arrival of the next breaking wave. Based on the assumption that $i_{b}$ is roller induced for $0 \leq t \leq 0.5 T_{p}$, the integrated roller related contribution $A_{r}$ to the increase of $I_{b}(x)$ reads

$$
A_{r}=\int_{0}^{0.5 T_{p}} \Delta I_{b} \exp ^{-\lambda t / T_{p}} \mathrm{~d} t=\frac{T_{p} \Delta I_{b}}{\lambda}\left(1-\exp ^{-0.5 \lambda}\right) .
$$

The integrated combined contribution $A_{b}$ of both the roller and persistent foam to the increase in $I_{b}(x)$ reads

$$
A_{b}=\int_{0}^{t_{c}} \Delta I_{b} \exp ^{-\lambda t / T_{p}} \mathrm{~d} t=\frac{T_{p} \Delta I_{b}}{\lambda}\left(1-\exp ^{-\lambda t_{c} / T_{p}}\right) .
$$

An expression for $t_{c}(x)$ can be found from the constraint that the combined intensity impact of the roller plus the persistent foam should yield a time-averaged intensity increase $I_{b}(x)-$ $I_{\min }$ for any $x$ along the cross-shore array, where $I_{\min }$ is the minimum intensity along $I_{b}(x)$. Adopting a wave-averaged approach where $t_{c}(x)$ is constant in time throughout the $10 \mathrm{~min}$ of 

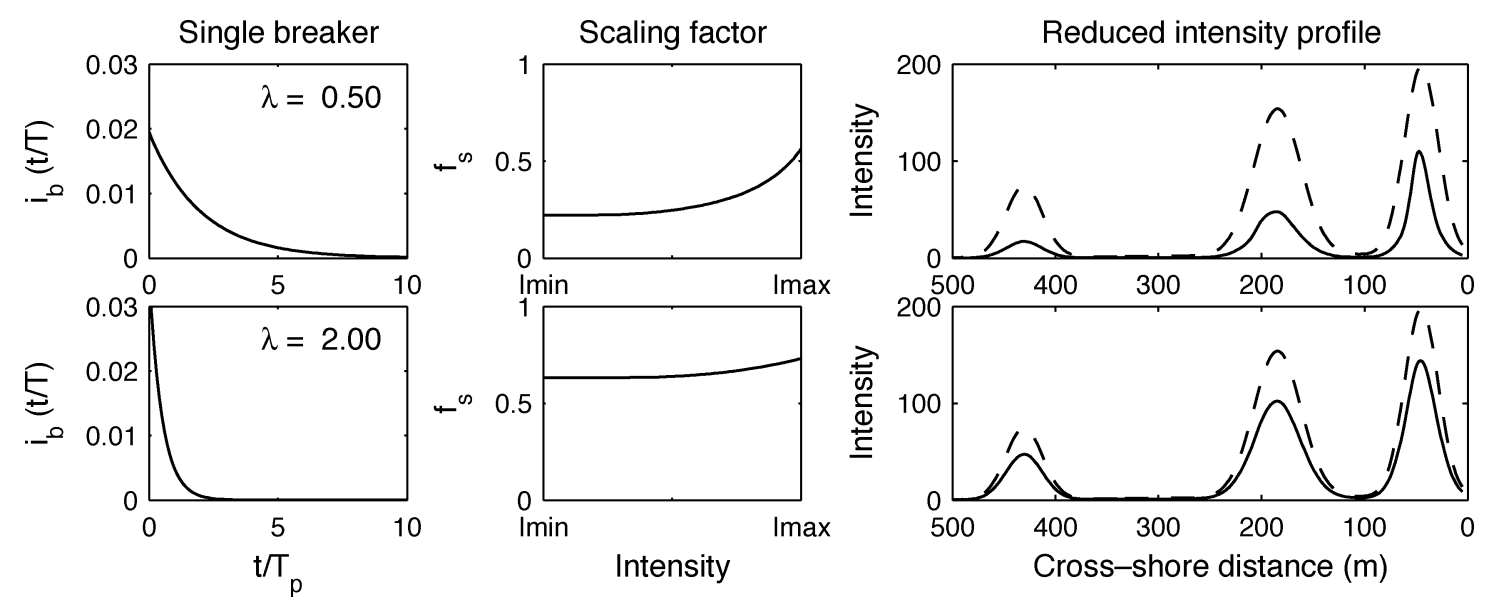

Fig. 7. Conceptual behavior of the persistent foam reduction model. The left-hand plots show the analytical representation of a roller with (upper plot) large and (lower plot) small amounts of persistent foam. The middle plots show $f_{s}$ as a function of $I_{b}$, indicating that persistent foam-polluted intensities need a larger reduction. The resulting scaled intensity profiles are shown in the right-hand plots (solid and dashed are $I_{r}$ and $I_{b}$, respectively).

time exposure for the collection of $I_{b}(x)$, this constraint can be formulated as

$$
I_{b}(x)-I_{\min }=\frac{A_{b}}{t_{c}}
$$

Thus

$$
t_{c}(x)=\frac{T_{p} \Delta I_{b}}{\lambda\left(I_{b}(x)-I_{\min }\right)}\left(1-\exp ^{-\lambda t_{c} / T_{p}}\right)
$$

which yields an implicit expression for $t_{c}(x)$ as a function of $\Delta I_{b}$, which is unknown yet. The value of $\Delta I_{b}$ can be quantified by assuming that all waves are breaking (i.e., saturated wave breaking conditions) at the location of maximum $I_{b}\left(I_{\max }\right)$. At this location, a new breaking wave thus arrives every $T_{p}$ seconds; time averaging of the instantaneous intensity signal $i_{b}(t)$ over the wave period $T_{p}$ should, therefore, yield the maximum intensity increase $I_{\max }-I_{\min }$

$$
I_{\max }-I_{\min }=\frac{1}{T_{p}} \int_{0}^{T_{p}} i_{b} \mathrm{~d} t
$$

and thus

$$
\Delta I_{b}=\frac{\lambda}{1-\exp ^{-\lambda}}\left(I_{\max }-I_{\min }\right) .
$$

Substitution of (13) into (11) allows to iteratively solve for $t_{c}(x)$ and $\Delta I_{b}$, which then enables the quantification of $A_{r}$ and $A_{b}$ from (8) and (9).

Finally, the scaling factor $f_{s}(6)$ is determined as the ratio of $A_{r}$ to $A_{b}$

$$
f_{s}(x)=\frac{A_{r}(x)}{A_{b}(x)} .
$$

This $f_{s}$ definition implies a reduction of $I_{b}(x)$ to account for roller-induced pixel intensities only. Reduction behavior is illustrated in Fig. 7 for different $\lambda$. With a decrease in $\lambda, I_{b}$ is increasingly obscured by persistent foam, which consequently yields a stronger reduction. Where mean intensities are low, the scaling factor is approximately constant. With increasing mean intensities, individual breaking waves start overlapping, which can be considered as a inherent correction mechanism of foam related intensities. Consequently, the scaling factor increases to a maximum at $I_{b}=I_{\max }$, where wave breaking is saturated and reduction is least required.

\section{C. $\lambda$ Parameterization}

The methodology to remove persistent foam developed in the previous subsection can only be applied when timestack images are available to estimate $\lambda$. As mentioned in Section II, such images are not collected routinely. For practical applications of (14), therefore, $\lambda$, which governs the time scale of the intensity decay after passage of a breaking wave, needs to be parameterized in terms of information contained in routinely collected images.

The analysis of the timestack images collected at Duck [Fig. 5(b) and (d)] has shown that an increase in $\lambda$ is associated with an increase in the peakedness of the time-varying intensity signal at saturated breaking, during the $10 \mathrm{~min}$ of time exposure for image collection. Standardly collected variance images [Fig. 1(c)] provide a measure for the variability of the intensity signal during the collection of a time exposure image, hence the peakedness of the intensity signal. Therefore, $\lambda$ is related to the standard deviation $\sigma_{I}$ of the intensity signal at saturated breaking $\left(I_{b}=I_{\max }\right)$, normalized with the time-averaged pixel intensity $I_{\max }$ at that location. It is hard to estimate $\lambda$ directly from the type of intensity time series shown in Fig. 5. Therefore, an indirect approach was adopted by estimating the ratio $t_{c} / T_{p}$ in the region of initial wave breaking, based on which $\lambda$ can be quantified. In the region of initial wave breaking, $t_{c}$ is equal to the period between the passage of roller and the (virtually) complete return of the intensity signal to the background level. Individual wave breaking events in the region of initial wave breaking thus allow for the estimation of $t_{c}$ from a $2-\mathrm{Hz}$ time series of pixel intensities. In total, 18 time series were processed. For each series, individual estimates of $t_{c}$ were averaged to yield a single $t_{c} / T_{p}$ for the investigated time series. The 18 resulting $t_{c} / T_{p}$ estimates varied between about 0.5 and 7.5 (Fig. 8), hence covering a representative range of wave breaking conditions. 


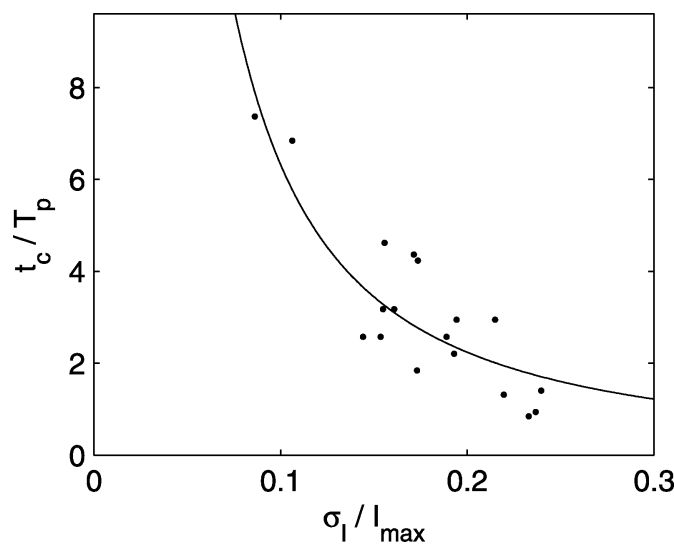

Fig. 8. Observed $t_{c} / T_{p}$ (symbols) versus $\sigma_{I} / I_{\max }$, based on 18 timestacks collected during the 1997 SandyDuck experiment [7]. The shape of the best fit curve ((18), solid line) was, as explained in the text, chosen such that the ratio $t_{c} / T_{p}$ approaches $\infty(0)$ for small (large) $\sigma_{I} / I_{\max }$.

The ratio $t_{c} / T_{p}$ thus estimated is associated with an integrated intensity contribution $A_{\text {est }}$ that nearly matches its theoretical maximum contribution $A_{\infty}$, which equals

$$
A_{\infty}=\int_{0}^{\infty} \Delta I_{b} \exp ^{-\lambda t / T_{p}} \mathrm{~d} t=\frac{T_{p} \Delta I_{b}}{\lambda} .
$$

Assuming that $A_{b}=A_{\mathrm{est}}=0.99 A_{\infty}$ results in

$$
\frac{T_{p} \Delta I_{b}}{\lambda}\left(1-\exp ^{-\lambda t_{c} / T_{p}}\right)=0.99 \frac{T_{p} \Delta I_{b}}{\lambda}
$$

which can be rewritten into

$$
\lambda=-\frac{\ln (1-0.99)}{t_{c} / T_{p}} .
$$

Parameterization of $t_{c} / T_{p}$ as a function of video-observed variables thus enables the quantification of $\lambda$. On the basis of the considerations given above, the ratio $t_{c} / T_{p}$ is parameterized as a function of $\sigma_{I} / I_{\max }$ at saturated breaking by means of an empirical expression of the form

$$
\frac{t_{c}}{T_{p}}=p\left(\frac{\sigma_{I}}{I_{\max }}\right)^{-b}
$$

where $p$ and $b$ are calibration parameters. Small values of $\sigma_{I} / I_{\max }$ (i.e., long tails) cause $t_{c} / T_{p}$ to become very large, whereas it approaches zero if $\sigma_{I} / I_{\max }$ becomes infinite. Both observations are in accordance with the physics of the process of consideration. The 18 timestacks collected at Duck suggest $b \approx 1.5$ and $p \approx 5$ (Fig. 8). Substitution of (18) into (17) finally yields the parameterized expression for $\lambda$

$$
\lambda=-p \ln (1-0.99)\left(\frac{\sigma_{I}}{I_{\max }}\right)^{b}
$$

with $b=1.5$ and $p=5$. Note that the arbitrarily chosen $A_{\text {est }} / A_{\infty}=0.99$ does not affect $f_{s}$ as a different choice would be compensated by a different $p$.

In summary, persistent foam is removed from $I_{b}(x)$ using a spatially-varying reduction function $f_{s}(6)$, which yields the crossshore distribution of roller related image intensities $I_{r}$. The latter will be used as a starting point for the comparison of video-derived and model-predicted proxies of wave dissipation. The sensitivity of this comparison to $p$ is investigated in Section V.

\section{WAVE TRANSFORMATION MODEL}

The wave model consists of three coupled differential equations which describe the time-averaged (over many wave periods) cross-shore evolution of organized wave energy $E$, roller energy $E_{r}$ and wave setup $\eta$. With the assumption that the wave field is narrowbanded in frequency and direction, the wave energy balance is

$$
\frac{\mathrm{d}}{\mathrm{d} x^{\prime}}\left(\frac{1}{8} \rho g H_{\mathrm{rms}}^{2} c_{g} \cos \bar{\theta}\right)=-D_{b}-D_{f}
$$

where $x^{\prime}$ denotes a coordinate system pointing onshore (this equation is solved in the direction of wave propagation), $\rho$ is water density, $g$ is gravitational acceleration, $H_{\text {rms }}$ is the rootmean-square wave height, $c_{g}$ is the group velocity, $\bar{\theta}$ is the mean wave angle, and $D_{b}$ and $D_{f}$ are breaking-wave dissipation and bottom friction, respectively. The $D_{b}$ formulation is given by [28]

$$
D_{b}=0.25 \alpha \rho g f_{p} \exp ^{-\left(H_{b} / H_{\mathrm{rms}}\right)^{2}}\left(H_{b}^{2}+H_{\mathrm{rms}}^{2}\right)
$$

in which $f_{p}=1 / T_{p}$ is the peak frequency and $H_{b}$ is given by [15]

$$
H_{b}=\frac{0.88}{k_{p}} \tanh \left(\frac{\gamma k_{p} h}{0.88}\right)
$$

where $k_{p}$ is the wavenumber evaluated with linear theory at the peak frequency and $h$ is the local water depth. The dissipation parameter $\alpha$ and the wave height to depth ratio $\gamma$ were set to default values ( $\alpha=1$ and $\gamma=0.5+0.4 \tanh \left(33 s_{0}\right)$ [29], where $s_{0}$ is the offshore wave steepness). Bottom friction is not important in the surfzone, where wave breaking dominates the dissipation. Linear wave theory is used to calculate $c_{g}$, and Snell's law is used to determine $\bar{\theta}(x)$ from offshore measurements. The balance equation for roller energy $E_{r}$ is [20], [30]

$$
\frac{\mathrm{d}}{\mathrm{d} x^{\prime}}\left(2 E_{r} c \cos \bar{\theta}\right)=-D_{r}+D_{b}
$$

where $c$ is the phase speed, and the roller-energy dissipation $D_{r}$ is

$$
D_{r}=\frac{2 \beta g E_{r}}{c} .
$$

The default value of the wave front slope $\beta$ is 0.1 [20], [30]. Finally, the wave setup $\eta$ is determined from the depth-integrated and time-averaged cross-shore momentum balance equation

$$
\frac{\mathrm{d} \eta}{\mathrm{d} x^{\prime}}=-\frac{1}{\rho g h} \frac{\mathrm{d} S_{x x}}{\mathrm{~d} x^{\prime}}
$$

where $S_{x x}=\left(n+n \cos ^{2} \bar{\theta}-(1 / 2)\right) E+2 E_{r} \cos ^{2} \bar{\theta}$, with $n=c_{g} / c$, is the cross-shore component of the radiation stress tensor [31].

The wave model is solved with a standard forward stepping scheme using the observed bathymetry, and offshore values of $H_{\mathrm{rms}}, T_{p}, \bar{\theta}$, and water level $\zeta$. One of the major assumptions in the model is the applicability of linear wave theory, even under breaking-wave conditions. Although nonlinear wave transformation is known to be important in surfzone conditions, in particular when considering long-period swell [12], model application against a spatially extensive (in the cross-shore) $500-\mathrm{h} H_{\mathrm{rms}}$ dataset collected at Egmond aan Zee [32] has shown that the 

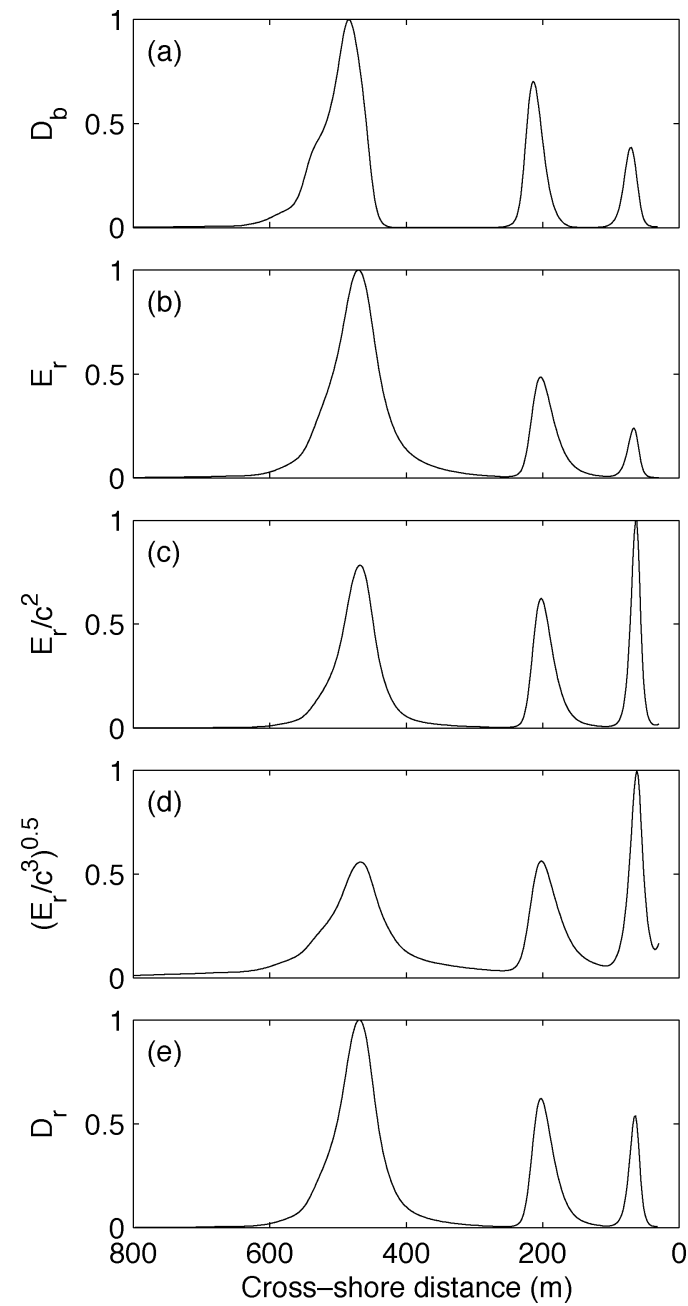

Fig. 9. Cross-shore shape of (a) $D_{b}$, (b) $E_{r}$, (c) $E_{r} / c^{2}$, (d) $\sqrt{E_{r} / c^{3}}$, and (e) $D_{r}$, based on offshore $H_{\mathrm{rms}}=1.5 \mathrm{~m}, T_{p}=8 \mathrm{~s}, \theta=30^{\circ}$, and $\zeta=0$, the depth profile in Fig. 2, and default model settings. Note that the height of the largest peak of each proxy was set to 1 .

model with its default settings can predict the cross-shore distribution of the observed $H_{\text {rms }}$ well during a wide range of conditions (offshore $H_{\mathrm{rms}}$ ranged between $0.2-3.9 \mathrm{~m}, T_{p}$ between 3.9 and $10.8 \mathrm{~s}$, and $\bar{\theta}$ between $\pm 45^{\circ}$ ). Model skill exceeded 0.89 at all sensors and the root-mean-square error for individual sensors varied between $0.10-0.16 \mathrm{~m}$, with an average of $0.13 \mathrm{~m}$ for all sensors. Also, the cross-shore structure of the time-averaged alongshore current, which is strongly dependent on the cross-shore structure of the roller dissipation, was predicted accurately during the same 500-h period [32]. This lends support to the use of the present wave model to predict the cross-shore structure of various hypothesized dissipation proxies.

The dissipation-related wave characteristics that, based on earlier research, are potentially good proxies of the cross-shore shape of $I_{b}$ include $D_{b}$ [13], $E_{r}$ [17], [18], $E_{r} / c^{2}$ [19], and $\sqrt{E_{r} / c^{3}}$ [21]. In addition, $D_{r}$ is included in the analysis, assuming that the generation of bubbles and foam is proportional to the transformation of kinetic energy to turbulence. An example of typical model output for these five parameters is provided in Fig. 9. As can be seen, the cross-shore distribution of the parameters differs in the precise location of the peaks, the width of the peaks, and the cross-shore change in the amplitude of the peaks. For example, for the condition shown in Fig. 9 the amplitude of each peak reduces in the onshore direction for $D_{b}, E_{r}$, and $D_{r}$, but increases for $E q_{r} / c^{2}$ and $\sqrt{E_{r} / c^{3}}$. Earlier research has shown that $D_{b}$ generally peaks too far seaward relative to the peak location of the observed intensity bands (e.g., [17]) and that $E_{r} / c^{2}$ may not result in the correct cross-shore evolution in the height of the observed peaks [21].

\section{COMPARISON}

\section{A. Data}

The data used to investigate which modeled dissipation proxy matches the cross-shore structure of $I_{r}$ best were collected during a six-week period in October-November 1998 as part of the Coast3D field experiment at the double barred-beach at Egmond aan Zee (e.g., Figs. 1 and 4), The Netherlands [17], [32], [33]. During the experiment, nearshore bathymetry was measured along 11 cross-shore profiles with $50-\mathrm{m}$ spacing alongshore, using a $15-\mathrm{m}$ high amphibious vehicle [33]. In total, 21 surveys were performed, of which 11 cover the inner subtidal bar only (because of harsh wave conditions, surveying of the outer bar was not always possible). The measured depth is estimated to have an error of less than $15 \mathrm{~cm}$, not accounting for unresolved bed forms having lengths less than $O(1 \mathrm{~m})$ and amplitudes less than $O(10 \mathrm{~cm})$. The survey data were interpolated to a rectangular grid with a cross-shore and alongshore spacing of 2 and $25 \mathrm{~m}$, respectively. Offshore hydrodynamic data required as input into the wave model were measured hourly with a directional wave buoy in $15-\mathrm{m}$ water depth.

The time exposure and variance images used here were recorded hourly by the Egmond video station, which is located $1500 \mathrm{~m}$ south of the mid of the Coast3D field site. Only images collected with camera 1 are considered here because on these images both the breaker zones associated with the inner and outer subtidal bar and the shorebreak are visible (e.g., Figs. 1 and 4). This camera is equipped with a 9-mm lens, which yields a spatial resolution along the central cross-shore array of the Coast3D site of $2-20 \mathrm{~m}$ in the cross-shore and about $50 \mathrm{~m}$ in the alongshore direction.

Here, we focus on $I(x)$ sampled over four different days along four cross-shore arrays with a 150-m alongshore spacing. Each $I(x)$ was taken as the alongshore average over a distance of twice the local alongshore pixel resolution centered around the $y$ coordinate of the array of interest. Because time-exposure images were collected hourly irrespective of the atmospheric and hydrodynamic conditions, not all $I(x)$ contain sufficient information for further processing. To avoid spurious results, $I(x)$ were culled from further analysis when one or more of the following criteria were met.

- $I_{0}$ was lower than 120 , indicating poor lighting conditions or nighttime images.

- Deviation $I-I_{G}$ exceeded 15 (at any $x$ ), indicating a poor fit of $I_{G}$ to $I$.

- $A_{G}$ of the highest peak did not exceed 20, indicating poorly pronounced dissipation peaks.

- $\sigma_{G}$ of the widest Gaussian peak exceeded 100, indicating unrealistically wide dissipation peaks.

- Standard deviation of $I_{b}(x)$ was less than 5, again indicating poorly pronounced dissipation peaks. 
TABLE I

MEAN AND STANDARD DEVIATION OF $\Delta x_{D}$ AND $\Delta A_{D}$ FOR VARIOUS MODELED DISSIPATION PROXIES

\begin{tabular}{l||l|rr}
\hline & $\widehat{D}_{c}$ & $\overline{\Delta x_{D}}(\mathrm{~m})$ & $\overline{\Delta A_{D}}$ \\
\hline \hline Outer subtidal bar & $D_{b}$ & 7.3 & -0.034 \\
& $E_{r}$ & 6.4 & 0.111 \\
& $E_{r} / c^{2}$ & 6.0 & -0.295 \\
& $\sqrt{E_{r} / c^{3}}$ & 6.2 & -0.333 \\
& $D_{r}$ & 6.3 & -0.070 \\
\hline Inner subtidal bar & $D_{b}$ & 17.1 & -0.037 \\
& $E_{r}$ & 8.1 & -0.012 \\
& $E_{r} / c^{2}$ & 5.7 & -0.122 \\
& $\sqrt{E_{r} / c^{3}}$ & 4.5 & -0.315 \\
& $D_{r}$ & 6.9 & -0.033 \\
\hline Intertidal bar & $D_{b}$ & 9.6 & 0.103 \\
& $E_{r}$ & 7.4 & -0.273 \\
& $E_{r} / c^{2}$ & 2.0 & 0.760 \\
& $\sqrt{E_{r} / c^{3}}$ & -1.2 & 0.411 \\
& $D_{r}$ & 5.0 & -0.096 \\
\hline Entire dataset & $D_{b}$ & 12.3 & 0.048 \\
& $E_{r}$ & 7.5 & -0.087 \\
& $E_{r} / c^{2}$ & 4.4 & 0.179 \\
& $\sqrt{E_{r} / c^{3}}$ & 2.6 & -0.042 \\
& $D_{r}$ & 6.0 & -0.009 \\
\hline
\end{tabular}

In total, $103 I_{G}$ profiles were accepted for further analysis [54\% of all sampled $I(x)]$ and converted into $I_{r}$ using $p=5$. These 103 profiles contained 239 dissipation peaks (48 at the outer subtidal bar, 100 at the inner subtidal, and 91 at the intertidal bar).

To enable a quantitative comparison of the cross-shore structure of $I_{r}$ and the modeled proxies of wave dissipation, the variables involved were normalized as

$$
\begin{aligned}
\widehat{D}_{o}(x) & =\frac{I_{r}(x)}{\int_{x} I_{r}(x) \mathrm{d} x} \\
\widehat{D}_{c}(x) & =\frac{D_{m}(x)}{\int_{x} D_{m}(x) \mathrm{d} x}
\end{aligned}
$$

where $\widehat{D}_{o}(x)$ is the normalized $I_{r}(x), D_{m}(x)$ is any of the five modeled proxies of wave dissipation identified above, and $\widehat{D}_{c}(x)$ is the normalized equivalent of $D_{m}(x)$.

\section{B. Results}

The comparison between $\widehat{D}_{o}(x)$ and $\widehat{D}_{c}(x)$ involved a comparison of the corresponding peak locations $\left(x_{D o}, x_{D c}\right)$ and peak areas $\left(A_{D o}, A_{D c}\right)$ below $\widehat{D}_{o}(x)$ and $\widehat{D}_{c}(x)$. The location $x_{D o}$ equals $\mu_{G} ; x_{D c}$ is the location of the corresponding local maximum of $\widehat{D}_{c}(x)$. Values of $A_{D o}$ and $A_{D c}$ were determined as the area below $\widehat{D}_{o}(x)$ and $\widehat{D}_{c}(x)$ within a distance $\sigma_{G}$ at both sides of $x_{D o}$ and $x_{D c}$, respectively. Results for the five wave characteristics investigated are shown in Table I using the mean $\overline{\Delta x_{D}}$ of the horizontal deviations $\Delta x_{D}=x_{D c}-x_{D o}$ and the mean $\overline{\Delta A_{D}}$ of the dimensionless area offset $\Delta A_{D}=$ $\left(A_{D c}-A_{D o}\right) / A_{D o}$. Negative (positive) $\overline{\Delta x_{D}}$ corresponds to a shoreward (seaward) offset of $x_{D c}$ as compared to the associated $x_{D o}$, while negative (positive) $\overline{\Delta A_{D}}$ reflect that $\widehat{D}_{c}$ underestimates (overestimates) the associated $\widehat{D}_{o}$ at a sandbar.
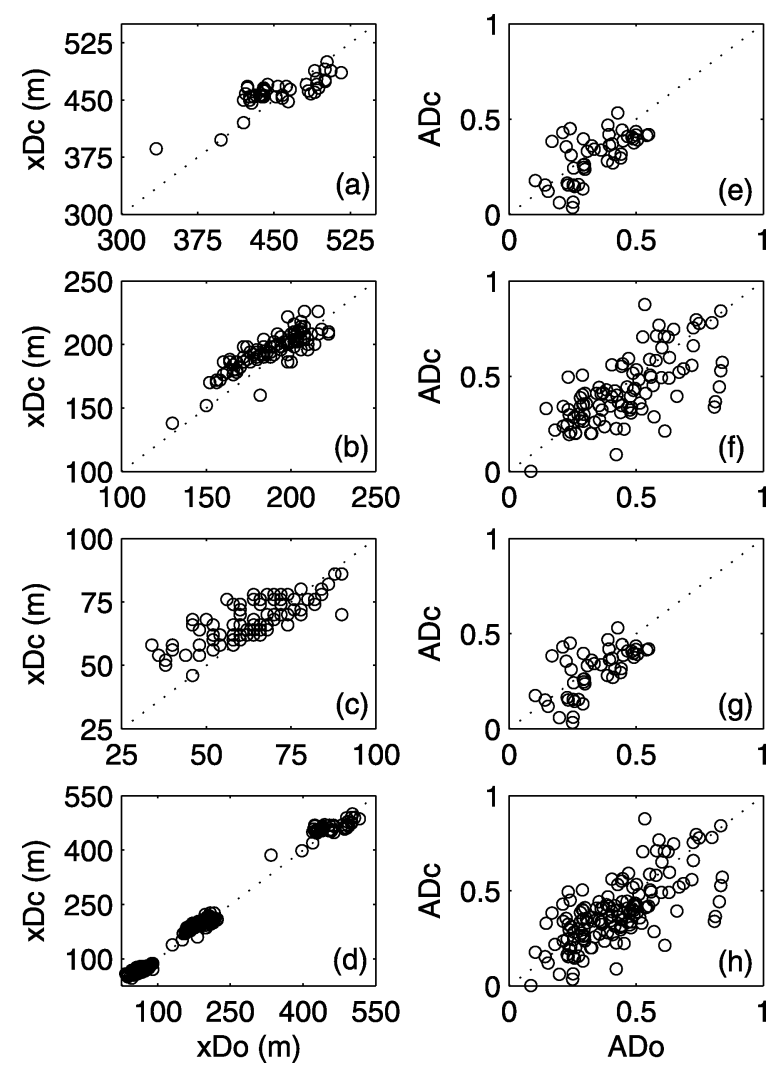

Fig. 10. (Left) $\widehat{D}_{r}$-based peak location $x_{D c}$ versus observed peak location $x_{D o}$ at (a) outer subtidal bar, (b) inner subtidal bar, (c) intertidal bar, and (d) all bars. (Right) $\widehat{D}_{r}$-based peak area $A_{D c}$ versus observed peak area $A_{D o}$ at (d) outer subtidal bar, (e) inner subtidal bar, (f) intertidal bar, and (g) all bars. The dotted lines in each plot are the line of equality.

Table I shows that normalized $D_{r}(x)$ (henceforth, a hat is used to indicate a normalized dissipation proxy) matches $\widehat{D}_{o}(x)$ best, because it combines moderate values of $\overline{\Delta x_{D}}$ at each sandbar with relatively small $\overline{\Delta A_{D}}$. The latter indicates a balanced distribution of the wave dissipation over the three sandbars. The other dissipation characteristics are rejected for various reasons. Although $\widehat{D}_{b}$ yields similar deviations in terms of $\overline{\Delta A_{D}}$ as $\widehat{D}_{r}$, the average seaward offset of $x_{D c}$ for $\widehat{D}_{b}$ is approximately twice as large as the offset for $\widehat{D}_{r}$ (Table I), consistent with [17]. Different performance of $\widehat{E_{r} / c^{2}}$ and $\sqrt{E_{r} / c^{3}}$ is best observed from $\overline{\Delta A_{D}}$ at each sandbar. Because $c \approx 0$ in very shallow water, $E_{r} / c^{2}$ and $\sqrt{E_{r} / c^{3}}$ yield $\widehat{D}_{c}(x)$ that considerably underestimate $\widehat{D}_{o}(x)$ at the outer subtidal bar, which is compensated by an overestimation of $\widehat{D}_{o}(x)$ at the intertidal bar (Table I), consistent with [19]. $\widehat{E}_{r}$ shows opposite behavior, with relatively large positive (negative) $\overline{\Delta A_{D}}$ at the outer (intertidal) bar relative to $\overline{\Delta A_{D}}$ based on $\widehat{D}_{r}$ (Table I). Scatterplots of $\widehat{D}_{r}$-based $x_{D c}$ and $A_{D c}$ versus $x_{D o}$ and $A_{D o}$, respectively, are provided in Fig. 10.

\section{Sensitivity Tests}

The results in Table I may have been affected by the values of the free parameters in the wave transformation model (most notably, $\gamma$ and $\beta$ ) and the foam reduction model $(p)$. To investigate this effect further, all three parameters were varied individually (that is, keeping the other two parameters at their default 
TABLE II

MEAN of $\Delta x_{D}$ AND $\Delta A_{D}$ AS A FUNCTION OF $\gamma, \beta$, AND $p$ FOR THE ENTIRE DATASET

\begin{tabular}{l|cr}
\hline & $\overline{\Delta x_{D}}(\mathrm{~m})$ & $\overline{\Delta A_{D}}$ \\
\hline default & 6.0 & 0.009 \\
\hline$\gamma=0.55$ & 8.2 & -0.107 \\
$\gamma=0.60$ & 7.6 & -0.059 \\
$\gamma=0.65$ & 6.9 & -0.017 \\
$\gamma=0.70$ & 6.1 & 0.020 \\
$\gamma=0.75$ & 5.4 & 0.052 \\
$\gamma=0.80$ & 4.8 & 0.081 \\
\hline$\beta=0.050$ & 1.9 & -0.071 \\
$\beta=0.075$ & 4.3 & -0.023 \\
$\beta=0.125$ & 7.3 & 0.028 \\
$\beta=0.150$ & 8.2 & 0.014 \\
\hline$p=1$ & 6.0 & 0.070 \\
$p=2.5$ & 6.0 & 0.017 \\
$p=10$ & 6.0 & 0.008 \\
$p=15$ & 6.0 & 0.009 \\
$p=20$ & 6.0 & 0.010 \\
$p=30$ & 6.0 & 0.010 \\
\hline
\end{tabular}

values) over a realistic range. Table II shows these ranges and summarizes the results by means of $\overline{\Delta x_{D}}$ and $\overline{\Delta A_{D}}$ for the entire dataset using $D_{r}(x)$ to compute $\widehat{D}_{c}(x)$.

Table II demonstrates that that $\overline{\Delta x_{D}}$ and $\overline{\Delta A_{D}}$ are not very sensitive to $\gamma$ variations in the range $0.60-0.75$. The onset of wave breaking is delayed with an increase in $\gamma$, which induces a minor $(<10 \mathrm{~m})$ shoreward shift of $x_{D c}$ and hence a decrease in $\overline{\Delta x_{D}}$. The parameter $\gamma$ settings also affect the distribution of the wave dissipation over the three sandbars. For $\gamma=0.55, \overline{\Delta A_{D}}$ amounts to $0.254,-0.157$, and -0.242 at the outer, inner, and intertidal bar, respectively, indicating that $\widehat{D}_{c}$ overestimates $\widehat{D}_{o}$ at the outer bar and underestimates $\widehat{D}_{o}$ at the inner and intertidal bar. With an increase in $\gamma, \widehat{D}_{c}$ decreases at the outer bar but increases further shoreward. For $\gamma=0.80$, however, $\overline{\Delta A_{D}}$ amounted to $-0.254,-0.059$, and 0.411 at the outer, inner, and intertidal bar, respectively, indicating that now $\widehat{D}_{c}$ underestimates $\widehat{D}_{o}$ at the outer bar, but overestimates it at the intertidal bar. None of the constant $\gamma$ settings outperforms the results of the default $\gamma$ setting according to [29].

The values of $\overline{\Delta x_{D}}$ and $\overline{\Delta A_{D}}$ are not very sensitive to $\beta$ variations in the range $0.075-0.125$. With a decrease in $\beta$, the dissipation of roller energy is delayed spatially, inducing a shoreward shift of $x_{D c}$. Because $x_{D c}$ was predicted to be, on average, seaward of $x_{D o}$ using $\beta=0.1$, lower $\beta$ values cause a $\overline{\Delta x_{D}}$ reduction to about $2 \mathrm{~m}$ for $\beta=0.05$. A decrease in $\beta$ is, however, also associated with a flattening and widening of the $D_{r}$ peaks, inducing an underestimation of $\widehat{D}_{o}$ for low $\beta$ (Table II). Best results in terms of both $\overline{\Delta x_{D}}$ and $\overline{\Delta A_{D}}$ are found for $\beta=0.10-0.125$.

Variation of the foam removal parameter $p$ does not affect $x_{D o}$ and, accordingly, $\overline{\Delta x_{D}}$ is independent of $p$ (Table II). With a decrease in $p, I_{\mathrm{G}}$ is increasingly corrected for persistent foam, inducing a narrowing of the $\hat{D}_{o}$ peaks and increasing relative difference in the amplitudes of the $\widehat{D}_{o}$ peaks. For $p<5$, this causes $\overline{\Delta A_{D}}$ to increase (Table II). For $p>5-10, \overline{\Delta A_{D}}$ is insensitive to $p$, indicating that the foam correction of $I_{\mathrm{G}}$ is small for these $p$.

\section{CONCLUDING REMARK}

In this paper, we have presented a method to (automatically) process cross-shore profiles of time-averaged image intensity obtained in a nearshore setting. Key elements in the method are: 1) the description of breaking-induced peaks as a cross-shore series of Gaussian shapes and 2) the removal of the intensity contribution of foam that after being generated in the breaking process remains floating at the water surface. The latter element is, after an investigation of instantaneous $2-\mathrm{Hz}$ intensity time series, parameterized using the ratio of the standard deviation $\sigma_{I}$ to the mean intensity $I_{\max }$ at saturated breaking. With a decrease in $\sigma_{I} / I_{\max }$ the time-averaged breaking-induced intensity is polluted increasingly by persistent foam, which consequently yields a stronger reduction of the Gaussian shapes. Based on video and bathymetric data collected at the double barred beach at Egmond aan Zee, The Netherlands and a standard wave transformation model containing the wave and roller energy balances, we conclude that the modeled cross-shore distribution of the dissipation of the roller energy $\left(D_{r}\right)$ matches the observed cross-shore shape of breaking-induced intensity $\left(I_{r}\right)$ well. Other hypothesized dissipation proxies result in a larger $(>10 \mathrm{~m})$ seaward bias in the locations of maximum breaking-induced intensity and model-predicted dissipation or do not predict the cross-shore change in the area below the breaking-induced intensity bands correctly. Initial results from the depth inversion using $D_{r}$, reported in [34], show remarkably improved results compared to those of Aarninkhof et al. [19]; also, the $D_{r}$-based depth estimates are more accurate than estimates obtained from phase speed of surface gravity waves [7], at least near the sandbar crests. These results will be presented in more detail elsewhere.

\section{ACKNOWLEDGMENT}

The authors wish to acknowledge R. Holman (OSU) for actively and generously stimulating the collaboration within the worldwide Argus research group.

\section{REFERENCES}

[1] E. P. Green, A. J. Edwards, and P. J. Mumby, "Mapping bathymetry," in Remote Sensing: Handbook for Tropical Coastal Management, A. J. Edwards, Ed. Paris, France: UNESCO, 2000, pp. 219-233.

[2] A. H. Benny and G. J. Dawson, "Satellite imagery as an aid to bathymetric charting in the Red Sea," Cartograph. J., vol. 20, pp. 5-16, 1983

[3] P. N. Bierwirth, T. J. Lee, and R. V. Burne, "Shallow sea-floor reflectance and water depth derived by unmixing multispectral imagery," Photogramm. Eng. Remote Sens., vol. 59, no. 3, pp. 331-338, 1993.

[4] J. C. Sandidge and R. J. Holyer, "Coastal bathymetry from hyperspectral observations of water radiance," Remote Sens. Environ., vol. 65, pp. 341-352, 1998.

[5] J. L. Irish and W. J. Lillycrop, "Scanning laser mapping of the coastal zone: the SHOALS system," ISPRS J. Photogramm. Remote Sens., vol. 54, pp. 123-129, 1999.

[6] D. R. Lyzenga, "Shallow-water bathymetry using combined lidar and passive multispectral scanner data," Int. J. Remote Sens., vol. 6, pp. $115-125,1985$.

[7] H. F. Stockdon and R. A. Holman, "Estimation of wave phase speed and nearshore bathymetry from video imagery," J. Geophys. Res., vol. 105, pp. 22 015-22 033, 2000.

[8] W. W. Williams, "The determination of gradients on enemy-held beaches," Geograph. J., vol. 109, pp. 76-90, 1947.

[9] J. P. Dugan, C. C. Piotrowski, and J. Z. Williams, "Water depth and surface current retrievals from airborne optical measurements of surface gravity wave dispersion," J. Geophys. Res., vol. 106, no. C8, pp. 16903-16915, 2001. 
[10] P. S. Bell, "Shallow water bathymetry derived from an analysis of X-band marine radar images of waves," Coast. Eng., vol. 37, pp. 513-527, 1999.

[11] J. A. McGregor, E. M. Poulter, and M. J. Smith, "S band doppler radar measurement of bathymetry, wave energy fluxes, and dissipation across an offshore bar," J. Geophys. Res., vol. 103, no. C9, pp. 18 779-18789, 1998.

[12] K. T. Holland, "Application of the linear dispersion relation with respect to depth inversion using remotely sensed imagery," IEEE Trans. Geosci. Remote Sensing, vol. 39, pp. 2060-2072, Sept. 2001.

[13] T. C. Lippmann and R. A. Holman, "Quantification of sand bar morphology: A video technique based on wave dissipation," J. Geophys. Res., vol. 94, pp. 995-1011, 1989.

[14] - "Phase speed and angle of breaking waves measured with video techniques," in Proc. Coastal Sediments'91, New York, 1991.

[15] J. A. Battjes and J. P. F. M. Janssen, "Energy loss and set-up due to breaking of random waves," in Proc. 16th Int. Conf. Coastal Engineering, New York, 1978, pp. 570-587.

[16] E. B. Thornton and R. T. Guza, "Transformation of wave height distribution,” J. Geophys. Res., vol. 88, pp. 5925-5938, 1983.

[17] I. M. J. Van Enckevort and B. G. Ruessink, "Effects of hydrodynamics and bathymetry on video estimates of nearshore sandbar position," $J$. Geophys. Res., vol. 106, pp. 16969-16979, 2001.

[18] B. G. Ruessink, P. S. Bell, I. M. J. Van Enckevort, and S. G. J. Aarninkhof, "Nearshore bar crest location quantified from time-averaged X-band radar images," Coast. Eng., vol. 45, pp. 19-32, 2002.

[19] S. G. J. Aarninkhof, P. C. Janssen, and N. G. Plant, "Quantitative estimations of bar dynamics from video images," in Proc. Coastal Dynamics'97, New York, 1997, pp. 365-374.

[20] M. J. F. Stive and H. J. De Vriend, "Shear stress and mean flow in shoaling and breaking waves," in Proc. 24th Int. Conf. Coastal Engineering, New York, 1994, pp. 594-608.

[21] S. G. J. Aarninkhof, "Quantification of bar bathymetry from video observations," Master's thesis, Delft Univ. Technol., Delft, The Netherlands, 1996.

[22] S. G. J. Aarninkhof and B. G. Ruessink, "Video observations of wave breaking and the implication for wave decay modeling," in Proc. Coastal Dynamics'01, New York, 2001, pp. 979-988.

[23] S. G. J. Aarninkhof and R. A. Holman, "Monitoring the nearshore with video," Backscatter, vol. 10, no. 2, pp. 8-11, 1999.

[24] K. T. Holland, R. A. Holman, T. C. Lippmann, J. Stanley, and N. Plant, "Practical use of video imagery in nearshore oceanographic field studies," J. Oceanic Eng., vol. 22, pp. 81-92, 1997.

[25] I. M. J. Van Enckevort, "Daily to Yearly Nearshore Bar Behavior," Ph.D. dissertation, Dept. Phys. Geograph., Utrecht Univ., Utrecht, The Netherlands, 2001.

[26] P. S. Alexander, "Quantitative analysis of nearshore morphological variability based on video imaging," Master's thesis, Oregon State Univ., Corvallis, 2001.

[27] S. Longo, M. Petti, and I. J. Losada, "Turbulence in the swash and surf zones: A review," Coast. Eng., vol. 45, pp. 129-147, 2002.
[28] T. E. Baldock, P. Holmes, S. Bunker, and P. Van Weert, "Cross-shore hydrodynamics within an unsaturated surf zone," Coast. Eng., vol. 34, pp. 173-196, 1998.

[29] J. A. Battjes and M. J. F. Stive, "Calibration and verification of a dissipation model for random breaking waves," J. Geophys. Res., vol. 90, pp. 9159-9167, 1985.

[30] R. B. Nairn, J. A. Roelvink, and H. N. Southgate, "Transition zone width and implications for modeling surfzone hydrodynamics," in Proc. 22nd Int. Conf. Coastal Engineering, New York, 1990, pp. 68-82.

[31] M. S. Longuet-Higgins and R. W. Stewart, "Radiation stress in water waves: A physical discussion with application," Deep Sea Res., vol. 11, pp. 529-563, 1964.

[32] B. G. Ruessink, J. R. Miles, F. Feddersen, R. T. Guza, and S. Elgar, "Modeling the alongshore current on barred beaches," J. Geophys. Res., vol. 106, pp. 22 451-22 463, 2001.

[33] B. G. Ruessink, I. M. J. Van Enckevort, K. S. Kingston, and M. A. Davidson, "Analysis of observed two- and three-dimensional nearshore bar behavior," Mar. Geol., vol. 169, pp. 161-183, 2000.

[34] S. G. J. Aarninkhof, B. G. Ruessink, J. A. Roelvink, and A. C. de Kruijf, "Quantification of surf zone bathymetry from video observations of wave breaking," in Proc. Coastal Sediments'03, New York, 2003.

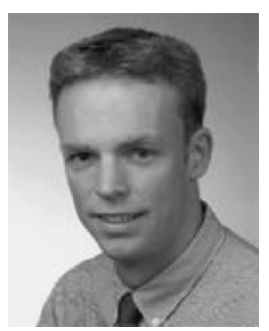

Stefan G. J. Aarninkhof received the Ph.D. degree in civil engineering from Delft University of Technology, Delft, The Netherlands, in 2003.

He is currently a Researcher/Adviser at WLIDelft Hydraulics' Marine and Coastal Management Division, Delft. His research interests include the development and application of morphodynamic models and video interpretation techniques in support of coastal management and science.

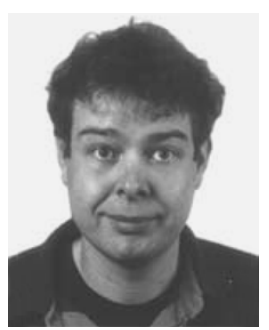

B. G. Ruessink received the Ph.D. degree in physical geography from Utrecht University, Utrecht, The Netherlands, in 1998.

$\mathrm{He}$ is currently an Associate Professor in coastal morphodynamics at Utrecht University. His research interests include the integration of nearshore remote sensing data into process-based numerical simulation models of nearshore bathymetry.

Dr. Ruessink is a member of the American Geophysical Union. 